Uniwersytet PrzyrodniczoHumanistyczny w Siedlcach

Siedlce University of Natural Sciences and Humanities

https://bazawiedzy.uph.edu.pl

\begin{tabular}{|l|l|}
\hline Publikacja / Publication & $\begin{array}{l}\text { Identification and structure of lampbrush sex bivalents prior to and after the } \\
\text { reproductive period of the European domestic goose Anser anser, } \\
\text { Andraszek Katarzyna, Smalec Elżbieta Maria, Tokarska Wioleta }\end{array}$ \\
\hline $\begin{array}{l}\text { DOI wersji wydawcy / Published } \\
\text { version DOI }\end{array}$ & http://dx.doi.org/10.3409/fb57_3-4.143-148 \\
\hline $\begin{array}{l}\text { Adres publikacji w Repozytorium } \\
\text { URL / Publication address in } \\
\text { Repository }\end{array}$ & https://bazawiedzy.uph.edu.pl/info/article/UPHdf16f978759a44a1bb2dd2f80cbd9c6e/ \\
\hline $\begin{array}{l}\text { Data opublikowania w Repozytorium / } \\
\text { Deposited in Repository on }\end{array}$ & 22 paź 2021 \\
\hline Rodzaj licencji / Type of licence & Other open licence _ \\
\hline & $\begin{array}{l}\text { Andraszek Katarzyna, Smalec Elżbieta Maria, Tokarska Wioleta: Identification and } \\
\text { structure of lampbrush sex bivalents prior to and after the reproductive period of the } \\
\text { Curopean domestic goose Anser anser, Folia Biologica-Krakow, vol. 57, no. 3, 2009, } \\
\text { pp. 143-148, DOI:10.3409/fb57_3-4.143-148 }\end{array}$ \\
\hline
\end{tabular}




\title{
Identification and Structure of Lampbrush Sex Bivalents Prior to and After the Reproductive Period of the European Domestic Goose Anser anser
}

\author{
Katarzyna ANDRASZEK, Elżbieta SMALEC and Wioleta TOKARSKA
}

Accepted April 20, 2009

\begin{abstract}
ANDRASZEK K., SMALEC E., TOKARSKA W. 2009. Identification and structure of lampbrush sex bivalents prior to and after the reproductive period of the European domestic goose Anser anser. Folia biol. (Kraków) 57: 143-148.

Lampbrush chromosomes (LBCs) present in bird oocytes are a new model in cytogenetics with particular significance for bird chromosome analysis. The fact that female birds are heterogametic makes it possible to observe both sex chromosomes in the form of decondensed structures typical of lampbrush chromosomes. A change in transcription activity associated with physiological processes in geese prior to and after the reproductive season is reflected in chromosome morphology. Lampbrush chromosomes obtained after the reproductive period have reduced side loops, sites of intensive transcriptional activity. However, noticeable characteristics in the chromosomes include inactive chromomeres. Chiasms, PBs, large side loops (ML) and telomeric loops (T, TLL, and GLL) are structures that undergo degradation latest after the termination of reproduction, and as a result, constitute the basis of identification of individual bivalents in different periods of the cell's transcriptional activity.
\end{abstract}

Key words: Anser anser goose, meiosis, lampbrush chromosomes (LBCs), lampbrush sex bivalent.

Katarzyna ANDRASZEK, Elizbieta SMALEC, Wioleta TOKARSKA, Institute of Bioengineering and Animal Breeding, University of Podlasie, Prusa 14, 08-110 Siedlce, Poland.

E-mail:andrasz@ap.siedlce.pl

Apart from a large diploid number and the presence of microchromosomes, heterogamety in females, connected with the presence of the ZW chromosomes, is a typical karyotype characteristic in birds. The bird $\mathrm{W}$ chromosome, similarly to the mammalian Y chromosome, in most species is often completely heterochromatic and is one of the smallest chromosomes in the karyotype.

Lampbrush chromosomes (LBCs) permit the analysis of the structure of both sex chromosomes and provide information on the expression of genes present in the lampbrushes. LBCs are greatly elongated diplotene bivalents found in the growing oocytes of all animals except mammals, some insects and some reptiles. The lampbrush form of even the smallest of chromosomes is easily visible and shows useful linear differentiation. It is particularly applicable in the case of the $\mathrm{W}$ chromosome which only in birds can be observed in the form of a large sex bivalent.

As a tool, lampbrush chromosomes were introduced into poultry cytogenetics by KROPOTOVA and GAGINSKAYA (1984), and by HUTCHISON (1987). The former authors support a thesis that chromosomes provide valuable information on bird gene expression and are irreplaceable in cytogenetic research on animals with small genomes in which a large number of small-sized mitotic chromosomes makes it impossible for scientists to carry out microchromosome analysis. In a report on the genome and karyotype of Gallus domesticus, LBCs have been recognized as a new model in avian cytogenetics (RODIONOV et al. 2005).

Lampbrush chromosomes found in different species are characterised by very similar structure, and they perform the same function. Utilisation of morphological similarity of amphibian and avian lampbrush chromosomes proved to be especially significant in overcoming stagnation in the analysis of avian karyotypes and genomes, particularly when the comparative analysis of avian and amphibian LBCs was applied (GAGINSKAYA et al. 1993). Structural similarity of LBCs is particularly visible in birds. Lampbrush chromosomes of domesticated birds are characterized by a similar location of chiasmata and marker loops. Basically they differ only in size and this may result from varying sizes of genomes of individual species (GREGORY 2002; RODIONOV \& CHECHIK 2002). 
The ZW bivalent, the structure of which is species-dependent, is an exception. Moreover, even within a single bird species, different forms of lampbrush sex bivalents have been observed (SOLOVEI et al. 1993; MIZUNO \& MACGREGOR 1998; RODIONOV et al. 2005). The ZW bivalent is most difficult to identify in the entire LBC set of a bird. It resembles a markedly asymmetric single chromosome which along its length is of predominantly typical lampbrush structure. The W chromosome is almost completely heterochromatic and often assumes a characteristic bar-like shape in the distal part of the $\mathrm{Z}$ chromosome. The $\mathrm{Z}$ and $\mathrm{W}$ chromosomes are connected by one chiasm in proximity to the telomere (MIZUNO \& MACGREGOR 1998).

Most analyses of lampbrush chromosomes pertain to gallinaceous birds, Gallus domesticus in particular. This provided the basis for the present research with the aim of identifying and describing the morphology of lampbrush sex bivalents prior to and after the reproductive period of the European domestic goose, Anser anser.

\section{Material and Methods}

Chromosomes in the form of lampbrushes were prepared by manual isolation from oocytes with diameters of $1.5-3.5 \mathrm{~mm}$ from sexually mature geese ( 10 before the reproductive period and 10 after the reproductive period) by applying a standard procedure (MACGREGOR \& VARLEY 1988) modified for bird oocytes (SOLOVEI et al. 1992; RODIONOV \& CHECHIK 2002). Preparations were stained with Coomassie Blue R 250. The number of LBCs analysed from each individual ranged from 5 to 10. Bivalent identification was carried out on the basis of marker structures typical of lampbrush sex bivalents (sex LBCs) described on bird lampbrush chromosomes (SOLOVEI et al. 1993; MIZUNO \& MACGREGOR 1998; RODIONOV et al. 2005). The following marker structures were observed on the lampbrush sex bivalents identified: TBLs - telomeric bow-like loops, MLs marker loops, DBLs - distal boundary loops, PBLs - proximal boundary loops, GLLs - giant lumpy loops, $\mathrm{CH}$ - chiasmata, $\mathrm{PBs}$ - protein bodies.

The preparations obtained were analysed under an Olympus BX 50 light microscope and were filed by means of an analogue Panasonic video camera. A detailed computer analysis was carried out by applying the Multiscan image analysing system, the Karyotype software, and graphic software compatible with the system.

Bivalents before the reproductive period were denoted by the small letter (a), bivalents after the reproductive period were denoted by the small letter (b). Marker structures of the bivalents were numbered with consecutive numbers.

\section{Results}

The ZW bivalent in birds is in the shape of an asymmetric univalent. One of the telomeres, the shape of which resembles a compact head, is treated as a condensed $\mathrm{W}$ microchromosome (HUTCHISON 1987; MIZUNO \& MACGREGOR 1998). The $Z$ chromosome, like the autosomes, is characterised by an arrangement of looped and non-looped regions typical of LBCs.

Three different lampbrush sex bivalents obtained from geese prior to their laying period (ZWa) are shown in Figure 1, whereas Figure 2 presents two different forms of lampbrush sex bivalents obtained from geese after reproduction (ZWb). Only well visible marker structures have

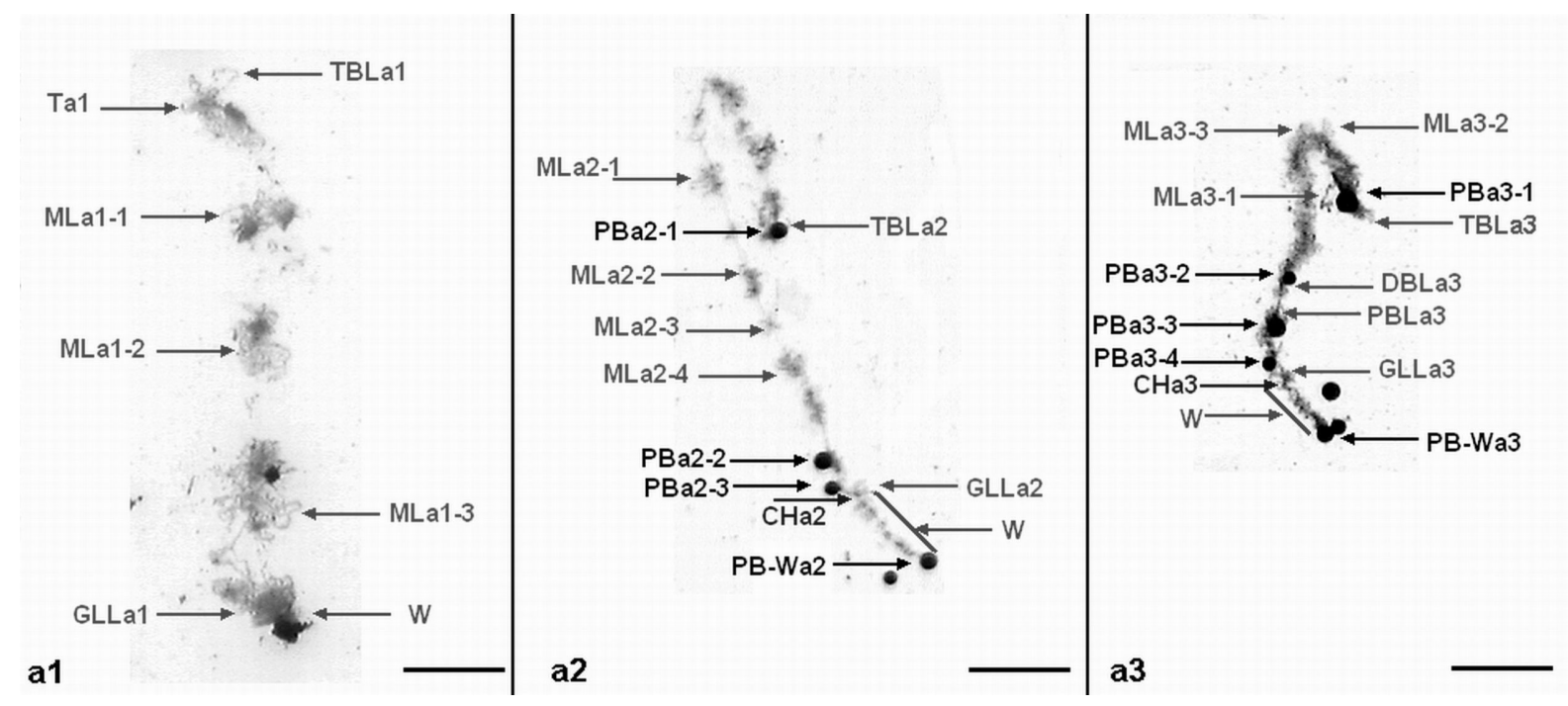

Fig. 1. Structure of lampbrush sex bivalents prior to the reproductive period. Arrows indicate marker structures of bivalents $\mathrm{Bar}=10 \mu \mathrm{m}$. 

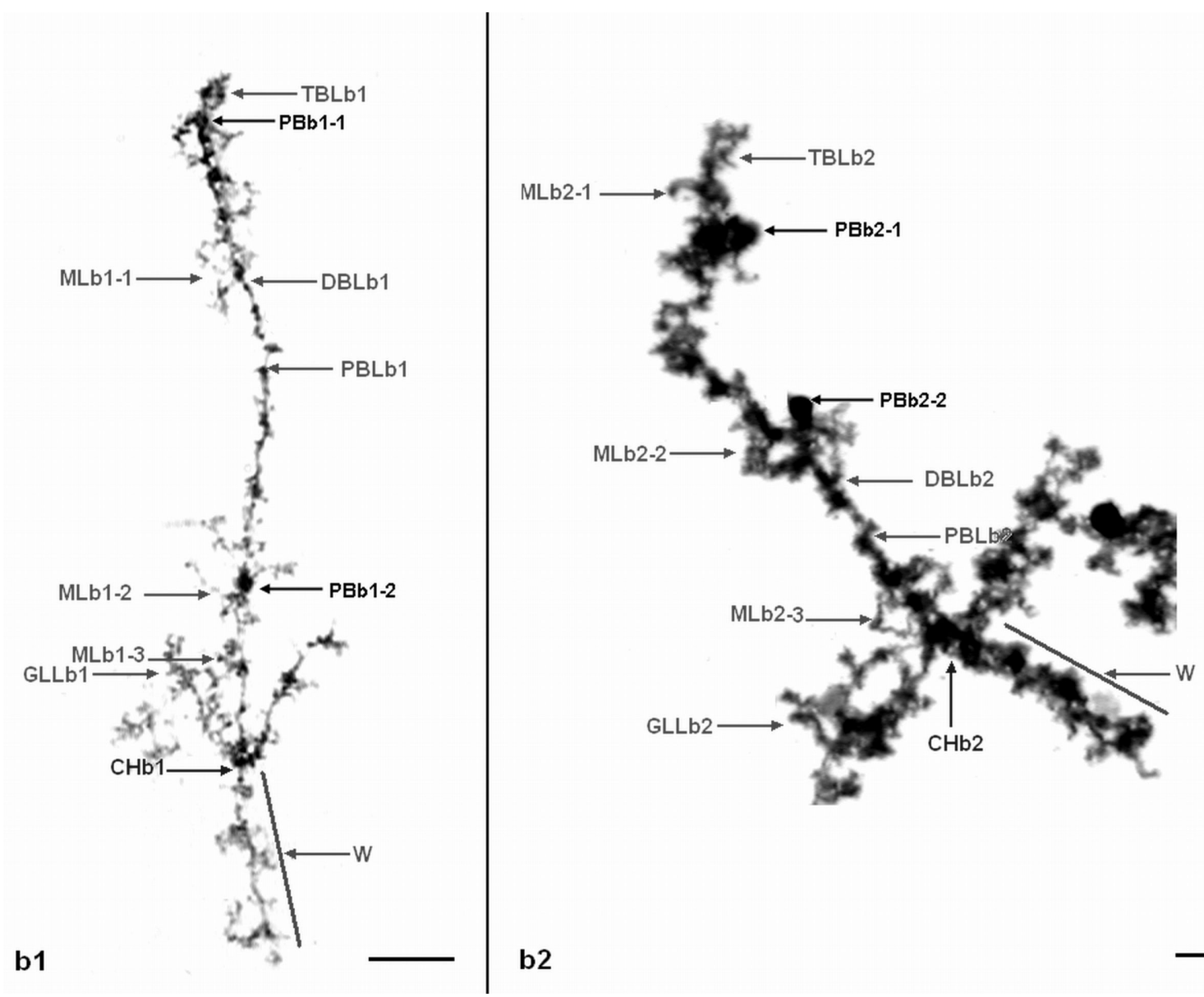

Fig. 2. Structure of lampbrush sex bivalents after the reproductive period. Arrows indicate marker structures of bivalents. $\mathrm{Bar}=10 \mu \mathrm{m}$.

been indicated on individual bivalents: $\mathrm{a} 1, \mathrm{a} 2$ and $\mathrm{a} 3$, as well as b1 and b2. The description of all the bivalent marker structures was abandoned because for clarity.

\section{Lampbrush sex bivalents (ZWa)}

TBL structures (TBLa1, TBLa2 and TBLa3) associated with the free telomere of the $\mathrm{Z}$ chromosome were identified on three bivalents ZWa. A proteinaceous structure $(\mathrm{PBa} 2-1)$ hides the TBL loop on bivalent a2. GLL structures (GLLa1, GLLa2 and GLLa3) were identified in the proximity of the chiasma linking chromosomes $\mathrm{Z}$ and $\mathrm{W}$. There are typical loops easily identifiable even on bivalents which have a compacted loop coat (fig. a3). Along the whole length of chromosome $\mathrm{Z}$ there occur centres of marker loops (ML) in strictly defined sites. They are best visible on chromosomes whose structures are less condensed (MLa1-1 - Mla1-3) figure a1. They also occur in sites on the chromosomes that are characterised by a denser loop structure (MLa2-1 - Mla2-4 and MLa3-1 - MLa3-3), figures a2 and a3, respectively. DBLa3 and PBLa3 structures (fig. a3) are loops flanking the centromere region of the sex bivalent. Two different-- sized protein bodies (PBa3-2 and PBa3-3) are located in their proximity on bivalent $\mathrm{a} 3$, and are connected with the chromatin of all three sex bivalents.

The $\mathrm{W}$ chromosome structure can be different and depends on the structure of the whole sex LBC. On the a1 bivalent, on which all the marker structures are in the shape of large side loops, the W chromosome occurs in the form of a heterochromatic lump. In contrast, on the 22 and a 3 bivalents, on which side loops are withdrawn to the chromosome axis and chromomeres can already be distinguished, the $\mathrm{W}$ chromosome is of a bar-like shape and is densely "spotted" with chromomeres. On each sex LBC presented there is one protein body associated with the $\mathrm{W}$ chromosome (PB-W).

\section{Lampbrush sex bivalents (ZWb)}

TBL structures associated with the free telomere of chromosome $Z$ were identified on two bivalents $\mathrm{ZWb}$. They consist of large bow-shaped telomeric loops (TBLb1 and TBLb2). Proteinaceous structures in the proximity of the TBL loop were found on bivalents $b 1$ and $b 2$ : a small one on bivalent $b 1$ (PBb1-1) and a large one on bivalent b2 (PBb2-1). 
On chromosomes $\mathrm{Z}$ of bivalents $\mathrm{b} 1$ and $\mathrm{b} 2$ three centres of marker loops MLb1-1 - MLb1-3 and MLb2-1 - MLb2-3 respectively, were identified. Both bivalent loops MLb1-2 and MLb2-2 are very well preserved and can be easily identified. They occur in the interstitial part of the bivalents and are connected with large protein bodies PBb1-2 and PBb2-2, respectively. Similarly, loops MLb1-3 and MLb2-3 are situated in the proximity of the chiasma linking chromosomes $\mathrm{Z}$ and W. GLL structures, as in bivalents a1, a2 and a3, were identified in the proximity of the chiasma linking chromosomes $\mathrm{Z}$ and W. In "post-laying" bivalents, GLL structures form very large loops which, in the case of bivalent $b 2$, constitute almost $30 \%$ of its length (GLLb2). In turn, loop GLLb1 takes an open form on bivalent $b 1$.

The structure of chromosome $\mathrm{W}$ is different and, as in the pre-reproduction bivalents, depends on the structure of the whole sex bivalent. On bivalent b1, loops are withdrawn towards the chromosome axis. Chromosome $\mathrm{W}$ has a similar structure. In turn, bivalent $\mathrm{b} 2$ of chromosome $\mathrm{W}$ has a typical heterochromatin club-like shape.

\section{Discussion}

A comparison of the structure of lampbrush sex bivalents obtained form geese prior to and after the reproductive period established that chiasmata, PBs, and marker structures such as large side loops (ML) and telomeric loops (TL and GLL) are structures which are the last to undergo degradation. The different portrayal of lampbrush sex bivalents obtained from geese prior to and after the reproductive period results from changes in transcriptional activity associated with physiological processes and is reflected in the chromosome mor- phological makeup. LBCs of geese prior to the reproductive period were characterised by large side loops indicating active transcription. Chromosomes obtained from geese after reproduction had small side loops and visible chromomeres, connected with decreased cell transcription activity (GALL 1983; GAGINSKAYA \& TSVETKOV 1988; GAGINSKAYA et al. 1993; MORGAN 2002).

In geese lampbrush sex bivalents, various forms of the ZW bivalent were observed both prior to and after the reproductive period, in accordance with descriptions for other domestic birds such as chicken, quail, turkey, pigeon (SOLOVEI et al. 1990, 1993; MYAKOSHINA \& RODIONOV 1994; MIZUNO \& MACGREGOR 1998; RODIONOV et al. 2005); as well as wild birds including sparrow and chaffinch (SOLOVEI et al. 1993; SAIFITDINOVA et al. 2003).

Distinctive TBL structures identified on goose sex LBCs prior to the laying period, occurring in the free $\mathrm{Z}$ chromosome telomere in other bird species, have been observed only in chickens (SOLOVEI et al. 1993; MizUNO \& MACGREGOR 1998). Loops do not occur on sex bivalents of quail, turkey, pigeon, sparrow and chaffinch (SOLOVEI et al. 1993; MYAKOSHINA \& RODIONOV 1994; MIZUNO \& MACGREGOR 1998; SAIFITDINOVA et al. 2003).

Large GLL loops constitute another characteristic structure of lampbrush sex bivalents localized in the region of chiasma connecting the $\mathrm{Z}$ and $\mathrm{W}$ chromosomes. In sex bivalents of geese, the loops are large and easily identifiable but not as clear as the enormous GLLs in turkey, pigeon, sparrow and chaffinch. Such structures have not been found on the quail chromosomes, whereas on chicken lampbrush sex bivalents the GLL structure may take forms ranging from small but considerably condensed loops to very large loops reaching a length

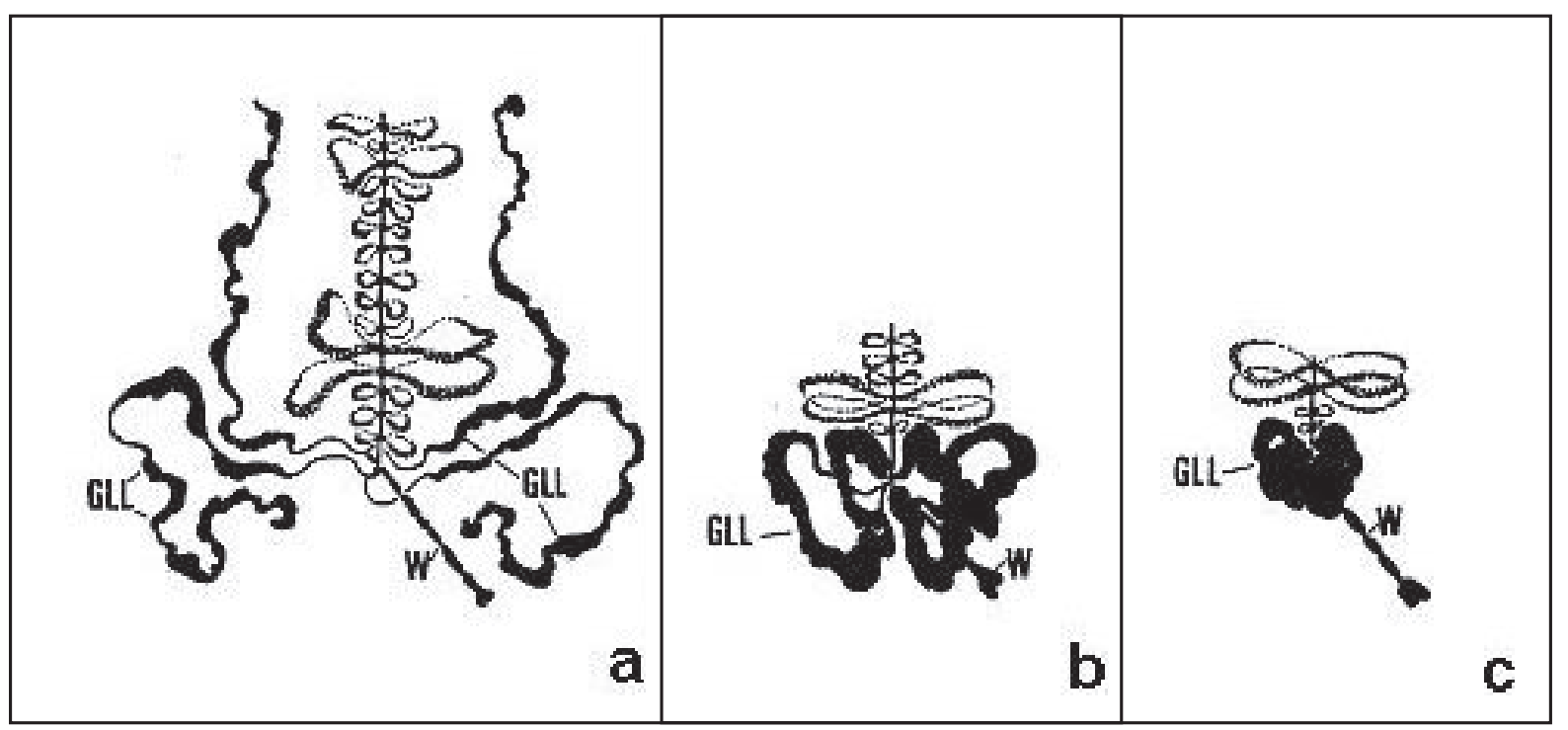

Fig. 3. Various loop forms GLL (according to SOLOVEI et al. 1993; modified). 
of up to one-third of the whole bivalent length. The loops may have a closed (a typical loop) or an open structure - Figure 3 (SOLOVEI et al. 1993; MIZUNO \& MACGREGOR 1998; SAIFITDINOVA et al. 2003).

Interestingly, the structure of goose lampbrush sex bivalents after the reproductive period shows very well preserved TBL loops on bivalents, as well as ML loops. Just like for pre-laying period bivalents, two markers ML are associated with protein bodies (PBs). In turn, in the proximity of chiasma linking chromosomes $\mathrm{Z}$ and $\mathrm{W}$, enormous GGL loops occur on post-laying bivalents. One of the analysed bivalents contained an open structure. GLL loops were also observed on sex bivalents of geese prior to reproduction, however, they were not as well developed. Various forms of GLL loops were observed in chicken, however, they were found only occasionally on chromosomes before the reproductive period (SOLOVEI et al. 1993). In turn, enormous GGL loops in the proximity of chiasma linking chromosomes $\mathrm{Z}$ and $\mathrm{W}$ were typical of lampbrush sex bivalents present in the oocytes of pigeon, chaffinch and sparrow (SOLOVEI et al. 1993; MIZUNO \& MACGREGOR 1998; SAIFITDINOVA et al. 2003).

Marker structures, called MLs, occur on goose lampbrush sex bivalents in different numbers and are of different size. ML structures have also been observed in other bird species. Their differentiation is a result of changes in cell transcriptional activity (GAGINSKAYA \& TSVETKOV 1988; MORGAN 2002). No marker loops have been detected within the $\mathrm{W}$ chromosome. The loops are typical of quail and pigeon bivalents (SOLOVEI et al. 1993; SAIFITDINOVA et al. 2003).

An interesting issue is the role and location of protein bodies. On goose sex bivalents, one PB has always been observed connected with the W chromosome, the remaining PBs have been found in various numbers and in different places on the bivalent. Protein bodies have not been observed on chicken, quail and turkey LBCs. By contrast, on pigeon, chaffinch and sparrow, sex bivalents PBs have been found at permanent sites. In the aforementioned species, one PB is always connected with the $\mathrm{W}$ chromosome. Moreover, in pigeon and chaffinch PBs occur in the centromeric segment of the lampbrush sex bivalent (SOLOVEI et al. 1993; SAIFITDINOVA et al. 2003; KRASIKOVA et al. 2004). A similar arrangement of PBs has been found on goose sex LBCs (Fig. 1a3).

Structures called protein bodies only occur in cells associated with LBCs. They are perfectly circular but differ in size and are linked with the chromosome axis of every LBC at regular intervals in the heterochromatin region (SOLOVEI et al. 1996; MORGAN 2002). With respect to morphology, PBs resemble Cajal bodies (CBs) which are associated with amphibian LBCs. However, immunocyto- chemical studies have revealed that PBs do not contain $\mathrm{p} 80$ coilin which is found in CBs. The distinctive composition of $\mathrm{PBs}$ indicates that they perform a completely different function than CBs. They may be involved in coordinating the spatial arrangement of chromosomes. Localisation of PBs is often connected with repeat sequences surrounding a centromere. Investigations of the potential role of proteins associated with centromeres and centromeric heterochromatin in biogenesis, as well as location of PBs, is a new field in studies on the structure of lampbrush chromosomes (GALL 2000; MORGAN et al. 2000; MORGAN 2002).

In conclusion, the use of lampbrush chromosomes in avian cytogenetics makes it possible to more broadly investigate the structure of microchromosomes, and is a unique chance to analyse the ZW bivalent. Particularly promising is the utilization of LBCs in research on transcriptional activity, gene mapping and cytogenetics.

\section{References}

Gaginskaya E., TsVetKov A. G. 1988. Electron microscopy research on the chromatin structure of dispersed lampbrush chromosomes in the hen. Tsitologia 30: 142-150.

Gaginskaya E., Rodionov A. V., Solovei I. V. 1993. Avian lampbrush chromosomes as a tool for high resolution chromosome mapping. Proc. of $8^{\text {th }}$ North American Colloquium on Domestic Animal Cytogenetics and Gene Mapping, Guelph, Ontario, Canada 117-118.

Gall J. G. 2000. Cajal bodies: the first 100 years. Ann. Rev. Cell. Dev. 16: 273-300.

Gall J. G., Diaz M. O., Stephenson E. C., Mahon K. A. 1983. The transcription unit of lampbrush chromosomes. Symp. Soc. Dev. Biol. 41: 137-146.

GREGORY T. R. 2002. A bird's-eye view of the c-value enigma: Genome size, cell size, and metabolic rate in the class aves. Int. J. Org. Evolution 56:121-130.

HuTCHISON N. 1987. Lampbrush chromosomes of the chicken, Gallus domesticus. J. Cell. Sci. 105: 493-500.

Krasikova A., Kulikova T., SAIFITdinova A., DERJUSheVA S., GaginskayA E. 2004. Centromeric protein bodies on avian lampbrush chromosomes contain a protein detectable with an antibody against DNA topoisomerase II. Chromosoma 113: 316-323.

Kropotova E. V., GAGINSKAYA E. 1984. Lampbrush chromosomes from Japanese quail oocytes. Tsitologia 26: 1008-1014.

MACGREGOR H. C., VARLEY J. 1988. Working with Animal Chromosomes. John Wiley \& Sons eds, London, New York, Brisbane, Toronto, Singapore.

Mizuno S., MACGREGOR H. C. 1998. The ZW lampbrush chromosomes of birds: unique opportunity to look at the molecular of sex chromosomes. Cytogenet. Cell. Genet. 80: 149-157.

Morgan G. T., Doyle O., Murphy C., Gall J. G. 2000. RNA polymerase II in Cajal bodies of amphibian oocytes. J. Struct. Biol. 129: 258-268.

MORGAN G. T. 2002. Lampbrush chromosomes and associated bodies: new insights into principles of nuclear structure and function. Chromosome Res. 10: 177-200.

Myakoshina Y. A., Rodionov A. V. 1994. Meiotic lampbrush chromosomes in turkey, Meleagris gallopavo (Galliformes: Meleagrididae). Genetika 30: 577-583. 
RODIONOV A. V., CHECHIK M. S. 2002. Lampbrush chromosomes in the Japanese quail Coturnix coturnix japonica: cytological maps of macrochromosomes and meiotic crossover frequency in females. Genetika 38: 1246-1251.

Rodionov A. V., GaLKina S. A., LuKina N. A. 2005. Maps of the lampbrush macrochromosomes of the chicken and Japanese quail. In: Second Report on Chicken Genes and Chromosomes 2005. Cytogenet. Genome Res. 109: 415-479.

SAIFITDinova A., DERJUSHEVA S., Krasikova A., GAGINSKAYA E. R. 2003. Lampbrush chromosomes of the chaffinch (Fringilla coelebs L.). Chromosome Res. 11:99-113.

Solovei I. V., Khutinaeva M. A., Chelysheva L. A., Rodionov A. V., GAGinsKaya E. 1990. Lampbrush sex bivalent of birds: identification and structure. Cytology 32: 817-825.

Solovei I. V., Gaginskaya E., Allen T., MacGregor H. C. 1992. A novel structure associated with lampbrush chromosomes in the chicken, Gallus domesticus. J. Cell Sci. 101: 759-772.

Solovei I. V., Gaginskaya E., Hutchison N.,. MACGREGOR H. C. 1993. Avian sex chromosomes in the lampbrush form: the ZW lampbrush bivalents from six species of bird. Chromosome Res. 1: 153-160.

Solovei I. V., Joffe B. I., Gaginskaya E., MACGREGOR H. C. 1996. Transcription of lampbrush chromosomes of a centromerically localized highly repeated DNA in pigeon $($ Columba) relates to sequence arrangement. Chromosome Res. 4: 588-603. 